\title{
Matching behavior of honeybees in a multiple-choice situation: The differential effect of environmental stimuli on the choice process
}

\author{
UWE GREGGERS and JULIANE MAUELSHAGEN \\ Freie Universität Berlin, Berlin, Germany
}

\begin{abstract}
The matching behavior of honeybees in a patch of four artificial feeders was studied under two different environmental conditions in order to examine the involvement of different stimuli in the choice process. Matching fails if all nearby landmarks are removed but can, under certain conditions, be restored by subsequently introducing odors, colors, or landmarks showing that there is no unique stimulus modality that provides matching. We propose two fundamentally different memory processes, both of which affect feeding behavior and support matching. We suggest that in one case, the probability of choice is determined by the strength of direct associations between locally perceived odor stimuli and reward rates. In the second case, simultaneously perceived color stimuli predict the relative reward rates indirectly by the spatial representation of the four feeders. Both memory processes are likely to interact and lead to efficient feeding behavior during foraging under natural conditions.
\end{abstract}

Foraging honeybees exhibit a great variety of behaviors, which have interested researchers for almost a century (Bitterman, 1988; Gould, 1984; Lindauer, 1963; Menzel, 1990; Opfinger, 1931; Seeley, 1989; von Frisch, 1967). Although the literature on foraging is strongly influenced by ultimate arguments and revolves around optimality criteria (Cheverton, Kacelnik, \& Krebs, 1985; Kacelnik, Houston, \& Schmid-Hempel, 1986), it is well known that honeybees have phenomenal learning capabilities with respect to the location, efficiency, and production cycles (timing) of different food sources (von Frisch, 1967; Gould, 1984; Heinrich, 1985; Menzel, 1990). Thus an analysis of the proximate mechanisms in the natural setting is called for. Supporting the idea that honeybees make specific use of their learning capabilities during foraging, Greggers and Menzel (1993) recently showed that honeybees foraging in a patch of four artificial feeding sites (feeders) matched their choice frequencies to the relative reward rates of the feeders-that is, they visited the higher rewarding feeders more frequently than the lower rewarding feeders. This applied to both "stay" flights (the bee revisits the feeder just visited) and "shift" flights (the bee chooses one of the three alternative feeders). Matching was first described by Herrnstein (1961) and refers to an appetitive choice behavior produced by concurrent reinforcement schedules of at least two alternatives. If the animal matches, the response rates to the

We are thankful to the referees for providing many constructive criticisms. We thank T. J. Carew, S. Fisher, M. Hammer, and R. Menzel for valuable commentary and criticism on earlier versions of the manuscript and A. Carney for essential help in preparing the English manuscript. Correspondence should be addressed to U. Greggers, Institut für Neurobiologie, Freie Universität Berlin, Königin-Luise-Str. 28-30, Berlin, Germany (e-mail: greggers@neuro.biologie.fu-berlin.de). alternatives reflect their relative reward rates (Herrnstein, 1961) or the relative amount of reward obtained after each choice (Catania, 1963). Thus the relative response rates of the animal should also be indicative of the quality or value of the different reinforcers. Matching requires that the animal be able to relate its response behavior to the reinforcement it receives. In addition, it is essential that the animal recognizes (i.e., remembers and perhaps compares) the specific alternatives in multiple-choice experiments in order to make the correct shift choices. Honeybees foraging in an arrangement of four alternatives thus need to be informed about the relative efficiency of each individual feeder in order to show matching. We propose that bees use specific memories that provide a link between the reward value of each feeder and the specific characteristics of its location. However, it is unclear which unique features of the feeding site, if any, are directly associated with the different sucrose rewards. The present study was designed to determine which stimuli characterizing the feeding place are essential for the bee to show matching. We specifically wanted to examine the kind of learning that takes place during matching.

There are numerous approaches and several well-established methods of analyzing the behavior of foraging bees at the feeding site, and many studies have investigated the role of stimuli at an artificial feeding place (Bitterman, 1988; von Frisch, 1967; Gould, 1984; Lindauer, 1963; Menzel, 1990; Opfinger, 1931). In particular, learning of the relationship between colors, odors, or landmarks and a sucrose reward has been extensively explored. It has become clear from these studies that even though the bee displays a stronger preference for odors than for colors and landmarks (Gould, 1984; Menzel, 1985 ) and for stimuli that appear before rather than after reinforcement (Gould, 1988; Grossmann, 1970; Menzel, 
1968; Opfinger, 1931, 1949), bees are able to learn any of the situations (Couvillon, Leiato, \& Bitterman, 1991; Grossmann, 1971; Hannes, 1930; Lehrer, 1991; Menzel, 1990). Most of these studies addressed the choice behavior of the bee after training with a single feeding site rather than with multiple feeding sites, and there are very few studies concerned with the nature of the rewarding stimulus itself (Bitterman, 1976; Menzel \& Erber, 1972). In order to examine matching, we monitored and manipulated the ongoing behavior of the bee rather than examining the performance of a bee in unrewarded extinction trials (see also Greggers \& Menzel, 1993). Moreover, the rewarding sucrose solution was supplied at a continuous and constant flow rate. This created a situation in which the amount of reward obtained varied between successive visits to a particular feeder depending on the sucrose flow rate and the time interval between successive visits to the same feeder. Thus the reward distribution was mainly shaped by the temporal behavior of the bee itself and was not determined by the experimenter (Greggers \& Menzel, 1993), which is the case in procedures that use common reinforcement schedules and unitary amounts of reward (Bitterman, 1988; Couvillon \& Bitterman, 1982; Grossman, 1970, 1971, 1973; Sigurdson, 1981a, 1981b).

In the present study, we examined the matching behavior of bees under two different environmental conditions, one that was rich in local landmarks and one that lacked local landmarks. We found that bees failed to match when all close landmarks that allow discrimination between the four feeders were removed, although foraging in the patch continued at random. In such a situation, matching can, under certain conditions, be restored by introducing odors, landmarks, or color stimuli. The present data demonstrate that the sequential access to local odors that mark the entrances of the feeders was sufficient to produce matching. However, the introduction of small local color marks did not produce matching, whereas large color marks, which could be viewed simultaneously by the bee, led to an uninterrupted choice process and supported matching.

\section{EXPERIMENT 1}

Single honeybees were trained to forage in a patch of four artificial feeders that supplied sucrose solution at different flow rates. In order to address the question of which stimuli are used by the bee to judge each feeder's reward rate and thus to adjust its choice frequency (matching), we installed an experimental setup on the roof of a building (about $6 \mathrm{~m}$ high; roof setup). In this way we created a situation that lacked any close landmarks except for those stimuli that were introduced by the experimenter. The idea was that if matching relies on nearby stimuli to identify each feeder, the removal of landmarks and of any other obvious stimuli that could signal a difference between the feeders would result in a lack of matching. This inability to orient at the feeding place would make it impossible for the bee to recognize a feeder and, therefore, to match.

In a first set of experiments, we created a "natural" environment in the roof setup by providing colors and landmarks and then tested for matching behavior. Then we compared the results to those obtained from the setup installed in the natural environment of a garden, where many nearby landmarks provided orientation for the bee at the feeding place (garden setup).

In the second set of experiments, we removed all stimuli from the roof setup to examine whether the remaining environmental stimuli were sufficient to support matching. In a parallel experiment in the garden, we blocked the bee's direct view of adjacent feeders, making the immediate environment around each feeder indistinguishable, and then tested the bee's ability to match (reducedcue garden setup).

\section{Method}

Single honeybees were trained to collect sucrose solution from four artificial feeders (Greggers \& Menzel, 1993). Each test bee was individually marked with colored dots. Other bees recruited by the test bee were removed from the setup immediately. Only bees that reliably visited all of the feeders and returned to the setup on a regular schedule were selected for the experiments. Each test bee remained alone in the setup for an average period of 3-5 days before the next anımal was trained. Data were collected during the late summer of 1992, 1993, and 1994.

General features of the setup. A single feeder was designed to supply $2 \mathrm{M}$ sucrose solution at a constant flow rate. The feeder consisted of an entrance (dianeter of $10 \mathrm{~mm}$ ) to a plastic tube with a rough inner surface ( $100 \mathrm{~mm}$ long and $25 \mathrm{~mm}$ wide). The bee had to pass through the tube to suck the sucrose solution from a glass capillary ( $10 \mathrm{~mm}$ long, $1 \mathrm{~mm}$ inner diameter). The glass capillary was connected to a piece of silicon tubing $(80 \mathrm{~cm}$ long, inner diameter of $0.7 \mathrm{~mm}$ ) that contained the sucrose solution. The solution was squeezed out of the tubing into the capillary at a constant speed that was set by a computer-controlled stepping motor. The flow rates of the four feeders were set to $0.5 \mu \mathrm{l} / \mathrm{min}, 0.25 \mu \mathrm{l} / \mathrm{min}$, $0.125 \mu \mathrm{l} / \mathrm{min}$, and $0.0625 \mu \mathrm{l} / \mathrm{min}$. Photodectectors installed at the entrance to the plastic tube recorded the number of choices of a particular feeder. In addition, the capillary was equipped with a set of photodetectors to detect the presence of the proboscis of the licking animal.

Garden setup. As in previous experiments (see Greggers \& Menzel, 1993) the four feeders were mounted vertically and symmetrically (at locations A-D) on a wall in the garden of the institute, a location where many local landmarks support orientation at the feeding place. The distance between the feeders was $1 \mathrm{~m}$. The entrances were marked with disks of the same color (Schott filter BG28 with aluminum reflector, diameter of $100 \mathrm{~mm}$ ). For the second set of experiments, in order to hide the closest landmarks and to obscure the direct view between adjacent feeders, four horizontal pillars ( $150 \mathrm{~mm}$ long) were mounted between the feeder entrances, and a layer of gray fabric was stretched across the wall and fixed to its edges (see Figure $1 \mathrm{a}$ and inset in Figure 3b).

Roof setup. The feeders were arranged horizontally and symmetrically (at locations A-D) on a white wooden box $(1.5 \times 1.5 \times$ $1.5 \mathrm{~m}$ ) that was mounted on a large metal rig. The distance between the feeders was $0.5 \mathrm{~m}$ (as already described by Greggers and Menzel, 1993, a variation of the distance between the feeders ranging between 0.35 and $2 \mathrm{~m}$ did not affect the matching behavior). All the instruments were hidden inside the box and could be accessed via 


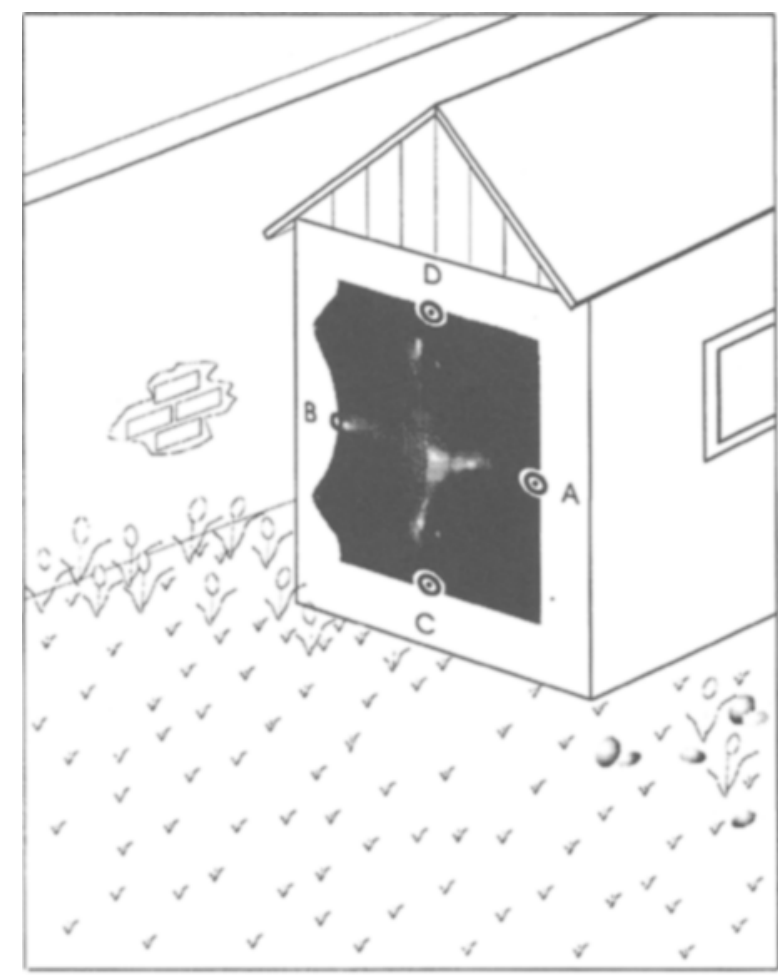

a

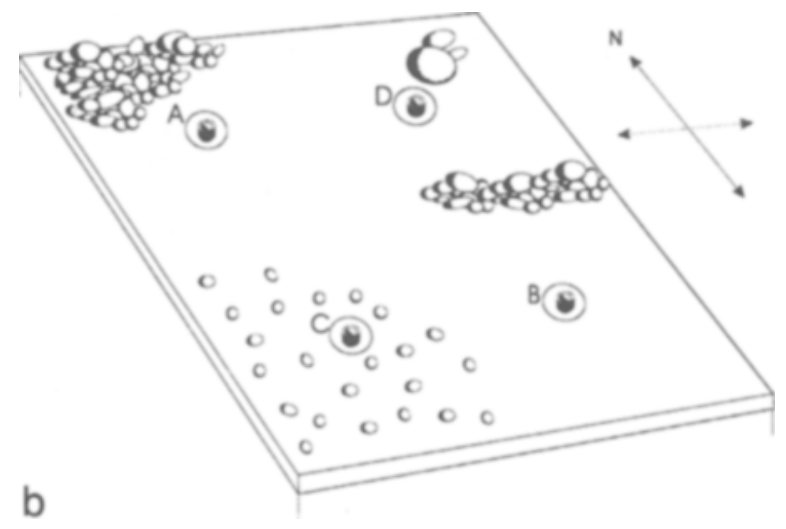

Figure 1. (a) The garden setup with four feeders mounted vertically and symmetrically (at locations A-D) on a wall of a hut, a location where many local landmarks support orientation at the feeding place. The distance between the feeders was $1 \mathrm{~m}$. The entrances were marked with disks of the same color (colored Schott filter BG28 with aluminum reflector and a diameter of $100 \mathrm{~mm}$ ). In order to hide the closest landmarks and to obscure the direct view between adjacent feeders, four horizontal pillars $(150 \mathrm{~mm}$ long) were mounted between the feeder entrances and a layer of gray fabric was stretched across the wall and fixed to its edges. (b) The roof setup, with four circles of green cardboard (HKS No. 65N, 220-mm diameter) as local cues and stones used as landmarks that were randomly placed on top of the table.

panels in the walls. The entrances were marked by red plastic rings protruding through the top panel of the table by about $15 \mathrm{~mm}$. As landmarks, we used either four circles of green cardboard $(\mathrm{K}+\mathrm{E}$ Druckfarben Stuttgart, HKS No. $65 \mathrm{~N}, 220 \mathrm{~mm}$ in diameter) and/or stones that were placed randomly on the top of the table (Figure lb).
Data analysis. The signals from the photodetectors were recorded in real time on a computer. The number of entrance signals of each feeder was counted for each bee. We concentrated on ranking shift flights to each feeder (as opposed to stay flights-i.e., when the bee visited two different feeders in sequence). Although matching of stay flights can be observed, when compared to the allocation of shift flights, the allocation of stay flights is influenced in a different manner, depending on the experimental arrangement used. Thus to varying degrees stay behavior may be considered to be directly involved in the choice process producing matching. Alternatively, it may be interpreted as a simple arousal reflecting the amount of reward experienced. We use the term ranking of shift flights to avoid confusion with perfect matching sensu Herrnstein (1961). In view of the variance in the experimental results, ranking of shift flights is the only constant measurable indicator to describe the degree to which matching is involved. For each bee, the number of shift flights was expressed as a percentage of visits per feeder, the total number of shift flights to all four feeders being $100 \%$. The mean choice frequencies were calculated from the relative percentages for all bees. The choice distributions among the four feeders were statistically analyzed by a one-way analysis of variance (ANOVA) for repeated measurements. The one-way ANOVA used here was designed to detect any possible difference between the mean choices of the four feeders within one experimental group. The first number in parentheses refers to degrees of freedom, which in experiments with four feeders is equal to 3 . The second number is degrees of freedom of error. Post hoc comparisons (LSD) between the feeders are given in full detail in Table 2. We compared the results evaluated by using parametric statistics (one-way ANOVA) with those evaluated by using nonparametric statistics (Friedman ANOVA of ranking for repeated measurements). Both methods revealed the same results.

A two-way ANOVA for repeated measurements was used for between-group comparisons. The two-way ANOVA used here was designed to detect possible differences between pairs of mean choices of feeders with the same rate from both groups. Standard errors were calculated for the individual bees. The number of bees and the number of choices they made are shown in the figure captions and in Table 1.

\section{Results}

In the first set of experiments, we compared matching in the roof setup with matching in the garden setup. The four feeders in the roof setup were marked by colored cardboard (HKS No. 65N, $220 \mathrm{~mm}$ in diameter), and stones were placed at random on top of the table (Figure $1 b$ ). In both the roof setup (Figure $2 a$ ) and the garden setup (Figure $2 b$ ), bees showed ranking - that is, they visited the higher rewarding feeders more frequently than the lower rewarding feeders [Figure $2 \mathrm{a}, F(3,21)=65.68$, $p<.0001$, Table 2a; Figure 2b, $F(3,39)=62.71, p<$ .0001 , Table $2 \mathrm{~b}]$. The resulting choice proportions obtained in both setups were indistinguishable from each other $[\mathrm{A}, F(1,20)=0.379$, n.s.; B, $F(1,20)=0.282$, n.s.; C, $F(1,20)=0.572$, n.s.; D, $F(1,20)=0.619$, n.s.). Furthermore, the time needed to establish ranking (one foraging bout, or 15-20 $\mathrm{min}$ ) was the same in both arrangements. Thus, when the roof setup was equipped with colors as a local cue and nearby landmarks, the bees received enough information to show "normal" ranking, as in the natural setup. In a separate experiment, they were also able to rank without the color marks, using a few stones as landmarks on top of the table $[n=1,941$ decisions of 4 bees, $F(3,9)=40.65, p<.0001$, Table $2 \mathrm{c}$; data 
Table 1

Relative Choice Frequencies at I ocations

\begin{tabular}{|c|c|c|c|c|c|c|c|c|c|c|c|}
\hline \multirow[b]{2}{*}{ Location } & \multirow[b]{2}{*}{ Experiment } & \multicolumn{2}{|c|}{$\mathrm{A}$} & \multicolumn{2}{|c|}{$\mathrm{B}$} & \multicolumn{2}{|c|}{$\mathrm{C}$} & \multicolumn{2}{|c|}{ [ } & \multirow[b]{2}{*}{ Bees } & \multirow[b]{2}{*}{ Choices } \\
\hline & & Choice & $S E M$ & Choice & $S E M$ & Choice & $S E M$ & Choice & $S E M$ & & \\
\hline \multicolumn{12}{|c|}{ Stay and Shift Behavior } \\
\hline Garden & Reduced-cue & 0.172 & 0.008 & 0.191 & 0.004 & 0.269 & 0.006 & 0.368 & 0.009 & 9 & 3,760 \\
\hline Garden & Long-term & 61 & 0.005 & 0.160 & 0.005 & 0.293 & 0.005 & 0.386 & 0.006 & 13 & 6,615 \\
\hline Roof & Green disks & 0.224 & 0.006 & 0.225 & 0.010 & 0.261 & 0.008 & 0.290 & 0.009 & 5 & 1,771 \\
\hline Roof & Stones & 183 & 0.007 & 0.188 & 0.003 & 93 & 0.010 & 0.336 & 0.010 & 4 & 2,366 \\
\hline Roof & Stones a & 0.186 & 0.004 & 0.185 & 0.004 & 0.276 & 0.005 & 0.352 & 0.007 & 8 & 4,058 \\
\hline Roof & Smal & 0.213 & 0.007 & 0.226 & 0.007 & & 0.006 & 0.303 & 0.007 & 7 & 5,026 \\
\hline Roof & Large colors & 0.160 & 0.004 & 0.167 & 0.005 & 0.281 & 0.004 & 0.391 & 0.006 & 7 & 6,380 \\
\hline \multicolumn{12}{|c|}{ Stay Behavior } \\
\hline den & $\operatorname{Red}$ & 76 & 0.006 & 17 & 0.007 & 0 & 0.011 & 08 & 0.014 & 9 & 792 \\
\hline den & Long & 0.094 & 0.005 & 0.1 & 0. & 9 & 0.008 & 0.501 & 0.010 & 13 & 1,677 \\
\hline Roof & Green disks & 0.145 & 0.006 & 0.083 & 0.0 & 0.275 & 0.005 & 0.497 & 0.009 & 5 & 374 \\
\hline Roof & Stones & 0.097 & 0.004 & 0.085 & 0.002 & 0.358 & 0.006 & 0 . & 0.006 & 4 & 425 \\
\hline Roof & Stones & 0.119 & 0.005 & 0.097 & 0.008 & 0.287 & 0.014 & 0.496 & 0.010 & 8 & 881 \\
\hline Roof & Smal & 0.106 & 0.009 & 0.117 & 0.021 & 0.299 & 0.008 & 0.479 & 0.022 & 7 & 1,199 \\
\hline Roof & Large colors & 0.086 & 0.009 & 0.089 & 0.010 & 0.305 & 0.012 & 0.519 & 0.015 & 7 & 1,382 \\
\hline
\end{tabular}

not shown]. However, without color as a local cue, it took them much longer (approximately 1 day, or about 10 foraging bouts) to manage this task.

In the second set of experiments, we asked if matching invariably depends on local landmarks, or if distant landmarks can substitute for local landmarks and provide enough cues to allow matching.

We removed all stimuli from the roof setup, leaving only the plastic rings (height $15 \mathrm{~mm}$ ) that marked the entrances to the four feeders. Bees foraging under these conditions, even for several days, showed no ranking in the graded reward situation, although they visited all of the feeders on a regular foraging schedule [Figure $3 \mathrm{a}$, $F(3,15)=0.853$, n.s., Table $2 \mathrm{~d}]$. Thus, recognition of specific feeders in the patch was impaired even though the situation allowed the bee to use prominent distant landmarks (at least $15 \mathrm{~m}$ from the setup), its sun compass (Dickinson, 1994; von Frisch, 1949), and the magnetic field of the earth (Collett \& Baron, 1994). To exclude the possibility that the entrance signals of the feeders were not visible enough from a distance of 0.5 to $0.7 \mathrm{~m}$ (a visual angle of $<1^{\circ}$ when viewed from another feeder), we used large cardboard disks (HKS $65 \mathrm{~N}, 220 \mathrm{~mm}$ in diameter) to mark the feeders in a symmetrical fashion in a separate experiment. But making the feeders more "visible" for the bee did not produce ranking $[n=1,397$ decisions of 5 bees, $F(3,12)=1.20$, n.s., Table $2 \mathrm{e}$, data not shown].

In the garden setup, we once again examined the possibility that the bee relies on individually distinguishable areas around each feeder (about $0.5 \mathrm{~m}$ around the entrance) in order to match (Figure $3 \mathrm{~b}$ ). In this reduced-cue experiment, we obscured the direct view of the adjacent feeders within this vertical arrangement (see Figure la and inset in Figure 3b). However, as shown in Figure 3b, ranking was not affected $[F(3,24)=41.93, p<.0001$,

\section{roof: stones $\&$ green disks}

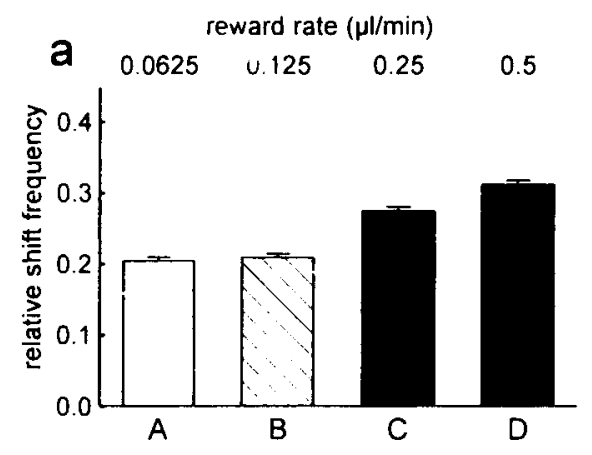

\section{garden: rich environment}

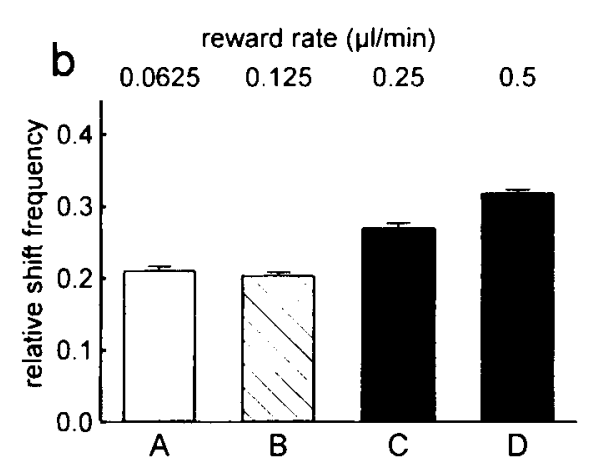

Figure 2. Relative choice frequencies to the four feeders arranged in the patch at locations A-D with sucrose flow rates as indicated (a) in the roof setup with stones as landmarks and feeder entrances marked by colored cardboard (see Figure $1 \mathrm{~b}$ ), $n=$ 3,177 decisions of 8 bees; and (b) in the garden setup with its natural rich environment, $n=3,584$ decisions of 14 bees. Choice proportions are plotted as mean values $\pm S E M$ (total number of each bee's shift flights to all four feeders $=1$ ). 
Table 2

Post Hoc Comparisons (LSD) Among Feeders

\begin{tabular}{|c|c|c|c|c|c|c|c|c|}
\hline & Location & Experiment & $\begin{array}{c}\mathbf{A}-\mathbf{B} \\
p< \\
\end{array}$ & $\begin{array}{c}\mathrm{A}-\mathrm{C} \\
p< \\
\end{array}$ & $\begin{array}{c}\mathrm{A}-\mathrm{D} \\
p<\end{array}$ & $\begin{array}{c}\text { B-C } \\
p< \\
\end{array}$ & $\begin{array}{c}\text { B-D } \\
p<\end{array}$ & $\begin{array}{c}\mathrm{C}-\mathrm{D} \\
p<\end{array}$ \\
\hline a & Roof & Stones and green disks & n.s. & .00001 & .00001 & .00016 & .00001 & .01779 \\
\hline $\mathrm{b}$ & Garden & Rich environment & n.s. & .00001 & .00001 & .00001 & .00001 & .00001 \\
\hline c & Roof & Stones & n.s. & .00002 & .00002 & .00006 & .00004 & n.s. \\
\hline d & Roof & No landmarks & n.s. & n.s. & n.s. & n.s. & n.s. & n.s. \\
\hline e & Roof & Large green disks & n.s. & n.s. & n.s. & n.s. & n.s. & n.s. \\
\hline f & Garden & Reduced-cue & n.s. & .00009 & .00001 & .00112 & .00001 & .00002 \\
\hline g & Roof & Odors & .00017 & .00001 & .00001 & .00001 & .00001 & .00001 \\
\hline h & Roof & Odors rotated by $90^{\circ}$ & n.s. & .00032 & .00006 & .00129 & .00023 & n.s. \\
\hline $\mathrm{i}$ & Roof & Odors removed & n.s. & n.s. & n.s. & .02402 & n.s. & .04622 \\
\hline k & Roof & $2 \times 2$ odors paired & n.s. & n.s. & n.s. & n.s. & n.s. & n.s. \\
\hline 1 & Garden & Long-term Phase 1 & n.s. & .00001 & .00001 & .00001 & .00001 & .00002 \\
\hline $\mathrm{m}$ & Garden & Long-term Phase 2a & n.s. & .00001 & .00001 & .00001 & .00001 & .01200 \\
\hline $\mathrm{n}$ & Garden & Long-term Phase 2b & n.s. & n.s. & n.s. & n.s. & n.s. & n.s. \\
\hline 0 & Garden & Long-term Phase $2 c$ & .00001 & .00001 & .00001 & .00001 & .00001 & .00001 \\
\hline $\mathrm{p}$ & Roof & Small colors & n.s. & n.s. & n.s. & n.s. & n.s. & n.s. \\
\hline q & Roof & Large colors & n.s. & .00001 & .00001 & .00001 & .00001 & .00001 \\
\hline $\mathrm{r}$ & Roof & Large colors rotated by $90^{\circ}$ & n.s. & .00001 & .00001 & .00005 & .00019 & .01707 \\
\hline $\mathbf{s}$ & Roof & Colors removed & n.s. & .00001 & .00001 & .00001 & .00001 & .02416 \\
\hline $\mathrm{t}$ & Roof & No landmarks/stay flights & .03871 & .00411 & .00001 & .28217 & .00106 & .01038 \\
\hline
\end{tabular}

Table 2f]. Thus matching does not necessarily require a direct view of adjacent feeders. Neither does it require specific stimuli around the individual entrances of the feeders (local cues), but is sufficiently supported by background stimuli (landmarks more than $0.5 \mathrm{~m}$ away).

Another interesting observation in the reduced-cue arrangement in the garden is that in the course of the $1 \mathrm{st}$ day, the bees explored the relationship between feeders and landmarks by backing off from the vertical arrangement and viewing it from some distance before making their decisions. Recording the flight paths of bees with a video camera showed that this behavior resulted in only $20 \%$ direct flights between any two feeders $( \pm 15 \mathrm{~cm}$ along a straight connecting line between the feeders), which indicates a random choice among the feeders (data not shown). However, within the next 2 days, the bees flew up to $70 \%$ along direct paths between feeders without backing off from the wall. Thus the bees learned to approach the targets by a relative orientation among nearby background features.

\section{Discussion}

The data of Experiment 1 offer some basic insight into the environmental conditions under which honeybees show matching while foraging in a patch of four artificial feeders: (1) If environmental stimuli are provided that allow the localization of each feeder in the patch, the choice frequencies of the feeders depend solely on the relative reward rates. This does not vary between the two conditions, which differed in several ways: horizontal versus vertical arrangement, distance between the feeders, and availability of nearby and distant landmarks. (2) If the bee in the roof setup is allowed to use only distant landmarks, its sun compass (Dickinson, 1994; von Frisch, 1949), and the magnetic field of the earth (Collett \& Baron, 1994), matching does not develop, even after several days of training. (3) However, as the data from the reduced-cue garden setup demonstrate, matching appears not to depend on specific stimuli in each feeder's immediate environment (radius of about $0.5 \mathrm{~m}$ ). Thus more distant landmarks are likely to be sufficient to provide the necessary cues. This indicates that matching can rely on landmark-based orientation, which provides more complex stimulus configurations and does not require specific local cues at the entrances of the feeders that predict the amount of reward.

In the course of several days in the reduced-cue garden setup, the flight paths between feeders became more direct and the bee's body angle of observation became more uniform. This suggests that although ranking develops within minutes, there are behavioral differences that may much later serve to optimize energy investment and landmark-based orientation. One possible explanation for this is that initially all landmarks available are used to localize the feeders relative to these landmarks. However, in the days following, orientation within the patch may become more specific, using environmental images that substitute for the simultaneous view of landmarks and feeders and thus may, since it relies on less detail, become independent of some of these landmarks. Other recent studies on landmark learning and visual navigation of insects have also discussed path guidance by image matching as one possible strategy of spatial orientation that involves a pixel-to-pixel matching of retinotopically fixed memory templates with the external environment covering a large area of the available visible space (Collett, 1995, 1996; Dill \& Heisenberg, 1995; Dill, Wolf, \& Heisenberg, 1995; Wehner, Michel, \& Antonson, 1996). Such a notion supports our view that the feeders need not be pinpointed by specific stimuli, but can be located by means of large-scale visual image matching with the surrounding background stimuli. 


\section{roof: no landmarks}

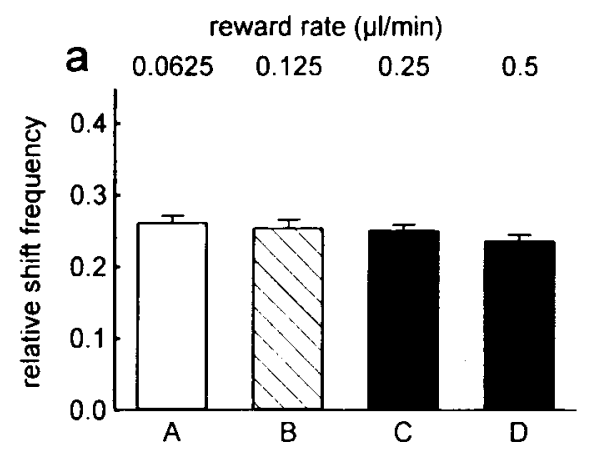

\section{garden: reduced cue}

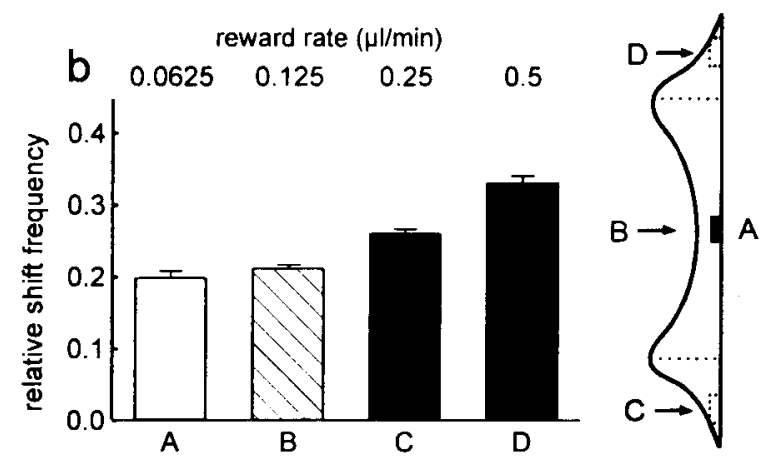

Figure 3. Relative choice frequencies to the four feeders arranged in the patch at locations $A-D$ with sucrose flow rates as indicated (a) in the roof setup without landmarks and with feeder entrances marked by small red plastic rings, $n=1,657$ decisions of 6 bees; (b) in the reduced-cue garden setup (see Figure 1a) with only background stimuli available, $n=2,968$ decisions of 9 bees. Using feeder $A$ as the viewing point, the inset illustrates how the other feeder entrances $(C, B, D)$ were hidden by the fabric stretched across pillars (dotted lines). Choice proportions are plotted as mean values $\pm S E M$ (total number of each bee's shift flights to all four feeders $=1$ ).

\section{EXPERIMENT 2}

The results of Experiment 1 showed that we could create a situation in which matching fails; thus we can test whether introducing some key stimuli restores the matching behavior. We were especially interested in the role of odor stimuli in matching, since in laboratory experiments odors have been learned as predictors of a sucrose reward in a single classical conditioning trial (Bitterman, Menzel, Fietz, \& Schäfer, 1983). With our current setup, we were able to examine whether stimulus-reinforcer associations are part of the matching behavior-that is, could odor become predictive of the reinforcer value by serving as a conditioned stimulus associated with the relative amount of reward supplied?

We designed the following experiment for the roof setup: In Phase 1 of the experiment (lasting 1.5 days), we introduced individual odor stimuli that could only be perceived locally. Thus the odors were feeder specific and were perceived sequentially from visit to visit. In Phase 2 (lasting $2 \mathrm{~h}$ ), we rotated the location of each feeder by $90^{\circ}$, leaving the odor stimuli with the original flow rates. If odor serves as a conditioned stimulus that also predicts the relative efficiency of a particular feeder and is the only cue that allows discrimination between the feeders, the bee should immediately switch its ranking to the new arrangement, irrespective of the location of the feeders. In Phase 3 (lasting $4 \mathrm{~h}$ ), the flow rates were rotated back to their former position, but now the odor marks were removed to test whether the bees had acquired any locational information about the four feeders.

In a second set of experiments, we used an arrangement of two low- and two high-rewarding feeders and marked the four feeders with two different odors in such a way that each odor was predictive of one low- and one highrewarding feeder.

A control experiment was run in the garden to examine how much time bees usually need to switch their choice frequencies after the relative locations of the flow rates were rearranged under these otherwise natural environmental conditions. As in the roof experiment, bees had to show ranking for 1.5 days in one given arrangement (Phase 1) before the flow rates were changed (Phase 2).

\section{Method}

The basic method, the arrangement of the two setups, and the sucrose flow rates of the four feeders were the same as in Experiment 1.

Roof setup. Odor stimuli were introduced to the otherwise bare roof setup. The odor stimuli were constantly supplied by a weak laminar flow $(5 \mathrm{ml} / \mathrm{sec})$ of odorous air that was introduced to the bottom part of the entrance tube of each feeder $(8 \mathrm{~cm}$ below the entrance). The outlets at the feeders had a diameter of $4 \mathrm{~mm}$. The air was supplied by a pump and was conducted through syringes that were filled with blotting paper carrying the odorous oils. The amount of odor used varied between 1 and $3 \mu$ ldepending on the odor and was determined empirically. The criterion was that the experimenters perceived a clear odor signal directly at the entrance of each feeder but were unable to smell the odors from more than 2-5 cm away. The odor concentrations were comparable to those used by Greggers and Menzel (1993). Their results indicated that feeders with the same flow rate of sucrose solution were chosen equally frequently, irrespective of whether the feeders were additionally marked with the same or different odors, and thus were distinguishable either by odor or location, or by location alone. The matching proportions found for the experiments with additional odors in the garden setup did not differ from those presented for the rich environment. The odors used were carnation, citral, octanol, and orange blossom, all of which were readily accepted by the bee. In order to avoid any effects of natural preference of one odor over the other, the odors signaling higher and lower rewarding feeders were switched in a subset of experiments.

In Phase 1 of the experiment, bees foraged in one arrangement for 1.5 days. In Phase 2 , the feeders were rotated by $90^{\circ}$, leaving each odor with its original flow rate. The rotation was done by moving the entire top plate of the setup to avoid contamination of the feeders with different odors. In Phase 3, the plate was rotated back to its original position (Phase 1), and the entrance tubes of the feeders were replaced by unscented tubes. 

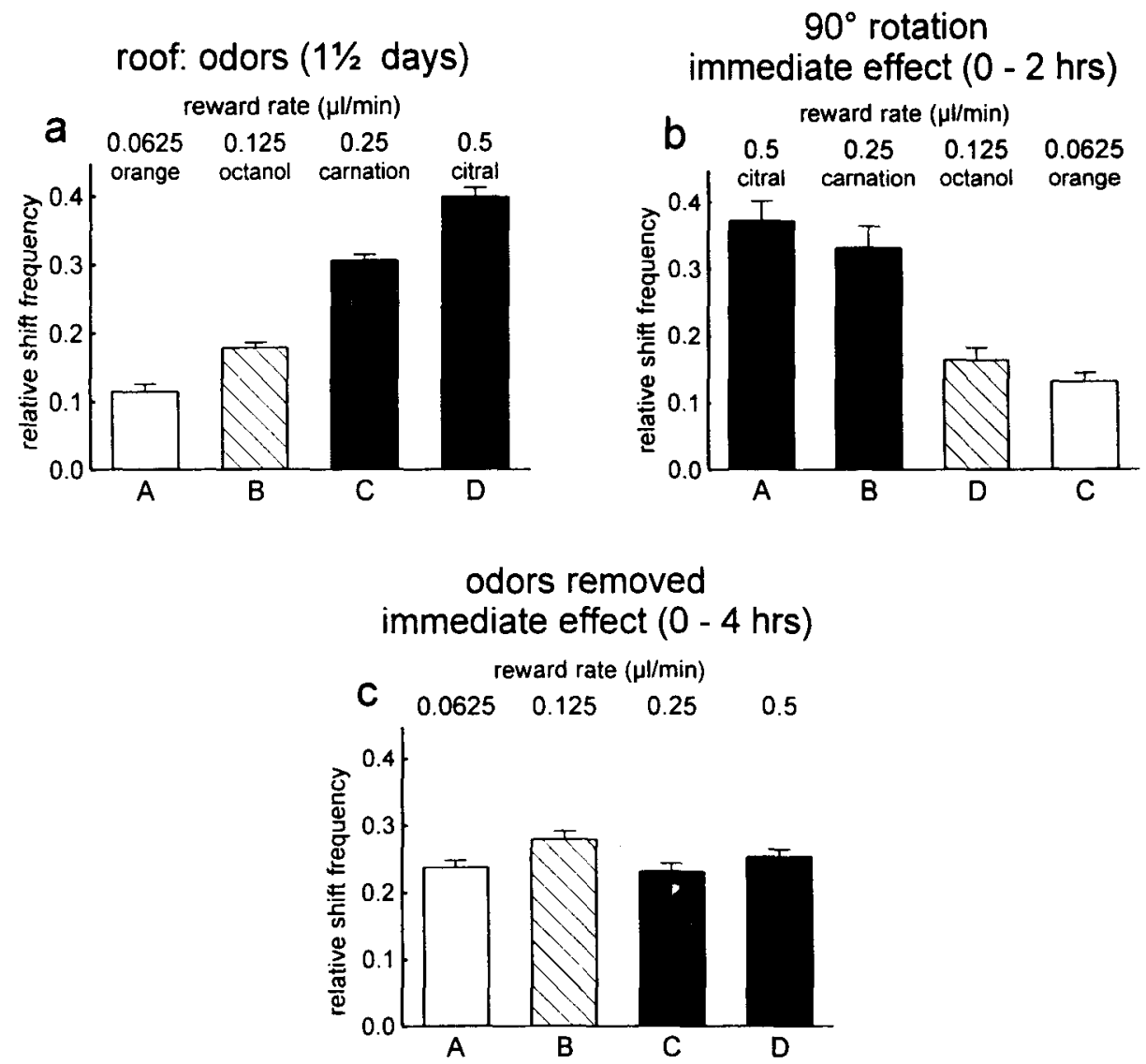

Figure 4. Relative choice frequencies in the roof setup without landmarks; feeder entrances marked by small gray plastic rings. The four feeders were arranged at locations $A-D$ with sucrose flow rates as indicated: (a) Phase 1 (1.5 days), with feeder entrances marked by odor, $n=4,179$ decisions of 5 bees; (b) Phase 2 ( 2 h), odor marks and flow rates rotated counterclockwise by $90^{\circ}, n=$ 640 decisions of 5 bees; (c) Phase 3 ( 4 h), flow rates as in (a), no odor marks, $n=1,308$ decisions of 5 bees. Choice proportions are plotted as mean values $\pm S E M$ (total number of each bee's shift flights to all four feeders $=1$ ).

In the second set of experiments, the two low- and two high-rewarding feeders supplied sucrose at $0.0625 \mu \mathrm{l} / \mathrm{min}$ and $0.5 \mu \mathrm{l} / \mathrm{min}$, respectively. Each of the two odors (orange and citral) was predictive of one low- and one high-rewarding feeder.

Garden setup. In all phases of the experiment, the entrances to the four feeders were equally marked by blue color disks. Again, in Phase 1 , bees had to show ranking in this arrangement for 1.5 days before the flow rates were switched in Phase 2. After the flow rates were switched, the formerly highest and lowest rewarding feeders now supplied the lowest and highest amounts of sucrose solution, respectively.

We analyzed the data of experimental Phase 2 in 2-h blocks, Phases $2 a-c$, in order to follow the time course of the bees' relearning the reversed reward arrangement and to allow for a direct comparison with experimental Phase 3 in the roof setup.

\section{Results}

Experiment 2 was designed to examine whether the introduction of individual odor marks would restore the matching behavior in the roof setup. The choice profiles found for the three phases of the experiment are summarized in Figures $4 a-4 c$. Figure 4a clearly demonstrates that with local odor cues in an otherwise poor environ- ment, bees exhibited an excellent ranking performance $[F(3,18)=183.3, p<.0001$, Table $2 \mathrm{~g}]$. In fact, the choice gradient was even steeper than ever in the garden setup $[\mathrm{A}, F(1,19)=76.10, p<.0001 ; \mathrm{B}, F(1,19)=7.117, p<$ $.016 ; \mathrm{C}, F(1,19)=11.61, p<.003 ; \mathrm{D}, F(1,19)=60.25$, $p<.0001$; compare Figure 2b]. This suggests that odors can be used to predict the relative reward rates of the feeders and thus to make the correct choices for matching. Furthermore, in Phase 2 the choice profile observed during the first $2 \mathrm{~h}$ after the $90^{\circ}$ rotation of the arrangement supports this assumption [Figure $4 \mathrm{~b}, F(3,12)=17.75$, $p<.0001$, Table $2 \mathrm{~h}]$. The bees switched their relative choice frequencies to the new arrangement much more quickly than after ranking for 1.5 days in the natural environment of the garden (compare Figure 6b). In fact, after a single foraging bout, the ranking profile had adapted completely to the new arrangement. After the odor marks were removed in Phase 3 of the experiment, the bees lost their ability to rank completely [Figure 4c, $F(3,12)=2.63$, n.s., Table 2i]. This shows that the bees were unable to localize the feeders relative to other cues 


\section{roof: odors paired}

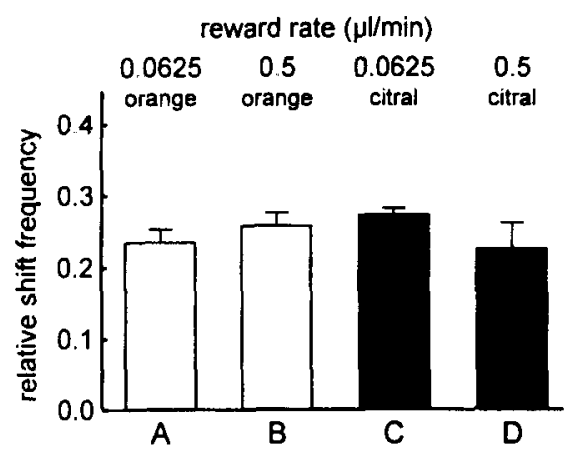

Figure 5. Relative choice frequencies in the roof setup without landmarks; feeder entrances marked by small gray plastic rings and odors as local cues. The four feeders were arranged at locations $A-D$ with sucrose flow rates as indicated. Choice proportions are plotted as mean values $\pm S E M$ (total number of each bee's shift flights to all four feeders $=1$ ), $n=976$ decisions of 4 bees.

(i.e., landmarks) during the earlier phases of the experiment. In conclusion, individual odors, even though perceived only sequentially, can carry all the information about the flow rates of the feeders. In this situation, the bee does not acquire additional information about the particular location of the feeders. This is again supported by the results of the second set of experiments (Figure 5): With the two odors (orange and citral), each signaling one high- and one low-rewarding feeder, the bee was not able to distinguish between the high- and low-rewarding feeders. As a result, they visited all four feeders equally frequently $[F(3,9)=0.413$, n.s., Table $2 \mathrm{k}]$.

In the control experiment in the garden setup, bees showed the normal ranking profile during Phase 1 [Figure $6 \mathrm{a}, F(3,36)=88.56, p<.0001$, Table 21]. Figure $6 \mathrm{~b}-$ $6 \mathrm{c}$ follow the choice profiles as formed during successive 2-h periods after switching the relative flow rates. In contrast to above experiment, the bee did not readily adapt its choice frequencies to the switched arrangement [Phase 2a, Figure 6b, $F(3,36)=34.3, p<.0001$, Table $2 \mathrm{~m}$ ], but began to relearn the new arrangement by the second 2 -h period [Phase $2 \mathrm{~b}$, Figure $6 \mathrm{c}, F(3,36)=0.391$, n.s., Table $2 \mathrm{n}]$. On average, the total relearning process took 6-8 h [Phase 2c, Figure 6d, $F(3,36)=22.93, p<$ .0001 , Table 2o)].

\section{Discussion}

In Experiment 2, we examined the effect of odor stimuli on the matching behavior. As the results clearly show, odors are sufficient to predict the relative flow rates of the four feeders and thus to provide matching. The rotation experiment (Phase 2) and subsequent removal of the odor stimuli (Phase 3 ) provide evidence that odors were the only cues in the roof setup used for matching. Apparently, the bee did not need to know the location of the feeders in order to differentiate between them. This is also supported by the observation that the bee randomly approached or landed at feeders (probably to sample the odor), but then frequently retreated to visit an alternative feeder. These results suggest that odors are directly associated with sucrose, so that odors become predictive of the various US strengths. Since the bee did not orientate according to nearby landmarks, the factor determining which feeder the bee collected from must have been odor. Thus in this case, decision making may have relied on a very simple probability rule: The higher the mean reward obtained, the higher the probability of collecting at a particular feeder. In order to form an expectancy of the mean reward supplied by each feeder, the bee would require only four separate memories for each odor, based on any or all previous visits, the strength of the association being relative to the mean amount of sucrose experienced. A simultaneous retrieval of these four memories to compare among them would not be required. In fact, the very steep gradient of the ranking profile also suggests that there is only minor, if any, interaction among these memories. However, such an elementary memory system works satisfactorily only in a very restricted way, as the results of the additional set of experiments demonstrate (Figure 5). We suggest that for each odor, there was a single memory that contained the mean expectancy of both the low- and the high-rewarding feeders. In contrast, previous experiments using the garden setup showed that odor marks, be they the same or different for the four feeders, do not interfere with normal choice behavior (Greggers \& Menzel, 1993). Thus in a more complex situation, as is likely to be found under natural conditions, a memory system that relies only on elementary CS/US associations would not be sufficient to account for matching. In turn, other memories that also provide location cues and that become connected to the information on the amount of reward to be expected seem to be essential for the evaluation of the efficiency of one feeding place with respect to others and, therefore, for a decision-making process that supports matching.

As the results of the control experiment in the garden suggest, once a bee has matched in a given arrangement for 1.5 days, relearning takes much longer than the initial learning of the situation. These results imply that in a situation in which bees are able to localize the feeders, they acquire some longer lasting form of memory. This long-term memory affects the behavior of the bee to such an extent that it will spend hours foraging at the "wrong" feeder after a reversal of the flow rates. Other branches of research concentrate on foraging behavior that relies on a minimum number of memory units to detect and exploit the richest sources in a variable environment (Real, 1991; Thuijsman, Peleg, Amitai, \& Shmida, 1995). We suggest that long-term memory plays an additional important role in foraging behavior.

\section{EXPERIMENT 3}

The results from the roof setup in Experiment 2 suggest that if no further location cues are provided, match- 

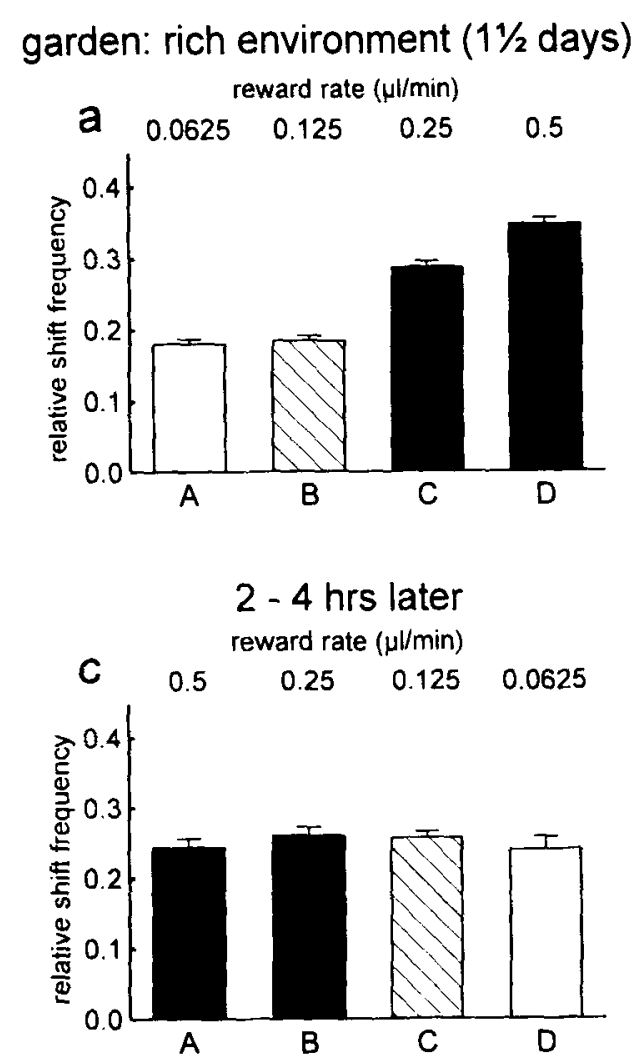

reward rates exchanged no immediate effect $(0-2$ hrs)
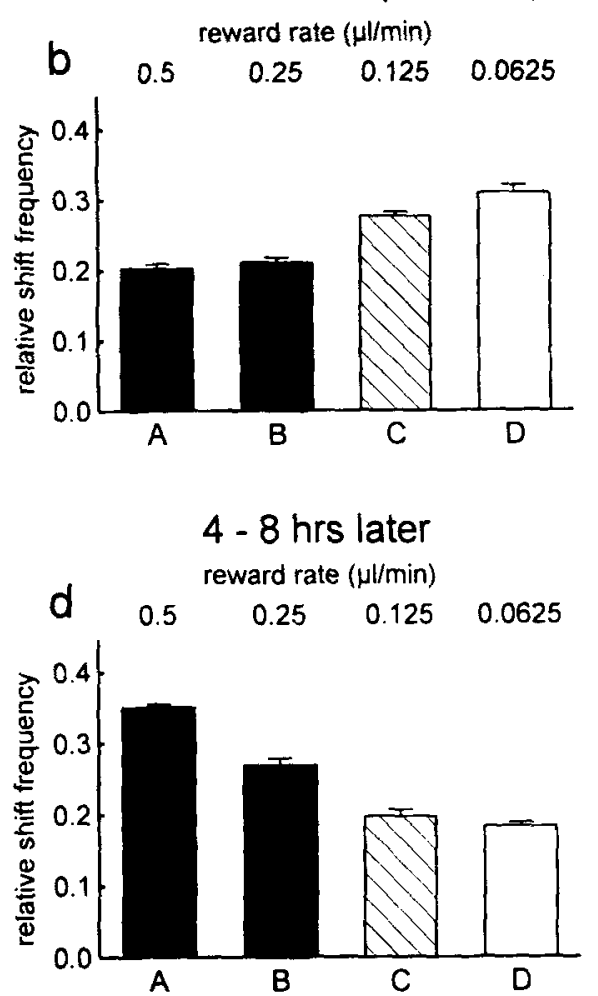

Figure 6. Relative choice frequencies in the garden setup with its normal rich environment. The four feeders were arranged at locations $A-D$ with sucrose flow rates as indicated: (a) Phase 1 (1.5 days), $n=4,938$ decisions of 13 bees; (b) Phase $2 \mathrm{a}(2 \mathrm{~h})$, flow rates exchanged, $n=1,786$ decisions of 13 bees; (c) Phase $2 \mathrm{~b}(2 \mathrm{~h})$ flow rates as in Phase 2a, $n=2,189$ decisions of 13 bees; (d) Phase $2 \mathrm{c}$ ( $4 \mathrm{~h}$ ), flow rates as in (b) and (c), $n=$ 2,749 decisions of 13 bees. Choice proportions are plotted as mean values \pm SEM (total number of each bee's shift nights to all four feeders $=1$ ).

ing can rely on a very elementary learning process - that is, simple CS/US associations between odor and sucrose solution. We were now interested in whether the same rules would also apply to color stimuli, especially since colors are the most commonly analyzed stimuli at the feeding place. In an analogy to Experiment 2, we designed a similar experiment for the roof setup using colors instead of odors: In Phase la of the experiment (lasting 1.5 days), we used "small" color marks to individually mark the entrances of the feeders. In this way, the bee was able to see the color of each feeder during the approach and departure flights. However, when leaving a feeder, the bee's compound eye could not resolve the colors of neighboring feeders because bees cannot resolve the color of an object that has less than $1^{\circ}$ of visual angle (Giurfa, Vorobyev, Kevan, \& Menzel, 1996; Menzel \& Greggers, 1985). Thus, like the odors in Experiment 2, the small color marks were feeder specific, were perceived sequentially from visit to visit, and were contiguous with the intake of sucrose solution.
To ensure that the bees can learn the small color marks, we tested the bees' ability to discriminate one rewarding feeder from three unrewarding feeders in a separate control experiment. During a training bout, the rewarding feeder was marked by a different color from that used for the unrewarding feeders. In the subsequent test, we counted choice during an extinction phase after placing the color marks at new locations (data not shown).

An additional phase of the experiments was introduced (Phase $1 \mathrm{~b}$, lasting 1 day), in which we exchanged the small color marks for "large" color marks. In this way, the bee was able to see the four colors simultaneously from any location in the setup (in contrast to the odors in Experiment 2). In Phase 2 (lasting $2 \mathrm{~h}$ ), we rotated the location of each feeder by $90^{\circ}$, leaving the large color stimuli with the original flow rate. Assuming that color could serve as a conditioned stimulus predicting the relative efficiency of a particular feeder, we would again expect the bee to immediately switch its ranking to the new arrangement, irrespective of the location of the feeders. In Phase 3, 

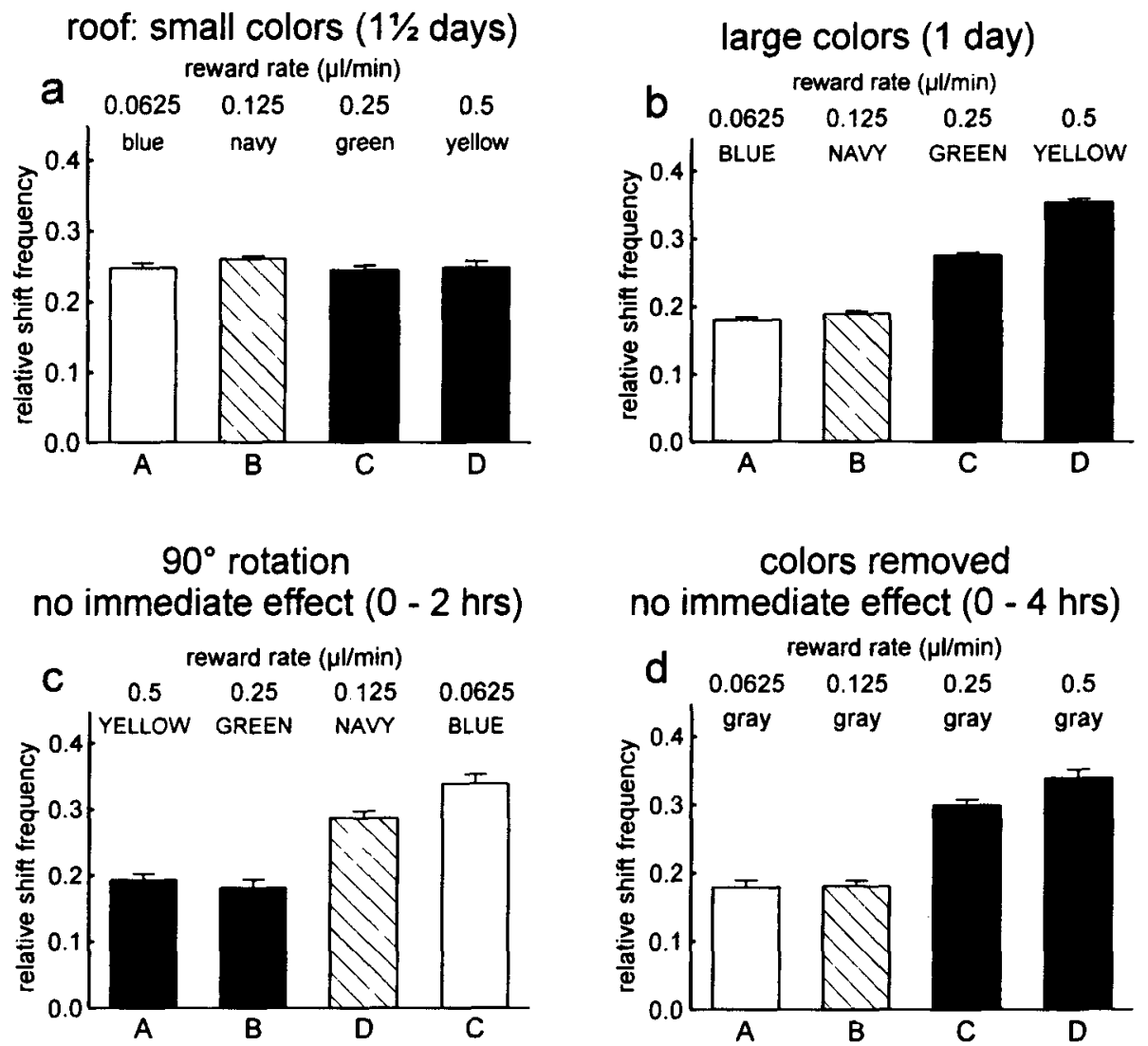

Figure 7. Relative choice frequencies in the roof setup without landmarks. The four feeders were arranged at locations A-D with sucrose flow rates as indicated: (a) Phase 1a (1.5 days), with feeder entrances marked by small colors, $n=3,827$ decisions of 7 bees; (b) Phase $1 \mathrm{~b}$ (1 day), entrances marked by large colors, $n=4,998$ decisions of 7 bees; (c) Phase 2 ( 2 h), large color marks and flow rates rotated counterclockwise by $90^{\circ}, n=1,370$ decisions of 7 bees; (d) Phase 3 ( 4 h), flow rates as in (b), feeder entrances marked by small gray plastic rings, $n=2,425$ decisions of 7 bees. Choice proportions are plotted as mean values $\pm S E M$ (total number of each bee's shift flights to all four feeders $=1$ ).

the flow rates were rotated back to their former position, but now the color marks were removed to test whether the bee had acquired any locational information.

\section{Method}

The basic method, the arrangement of the two setups, and the sucrose flow rates of the four feeders were again the same as in Experiments 1 and 2 .

Roof Setup. In Phase 1 of the experiment, the entrances of the feeders were marked by small color marks. Small color marks were cylinders of colored cardboard (blue-HKS No. 50; navy--HKS No. 39N; green-HKS No. $65 \mathrm{~N}$; yellow-HKS No. $3 \mathrm{~N}$ ). These were $15 \mathrm{~mm}$ high, which is smaller than $1^{\circ}$ of visual angle if viewed from a distance of $0.5-0.7 \mathrm{~m}$ (distance between the feeders). Thus from the entrance of a neighboring feeder, the colors could not be resolved by the bee's compound eye. Large color marks, as used in Phase 2 of the experiment, were hat-shaped and made of the same colored cardboard as the small color marks. The cylindrical part surrounding the entrance tube was raised by $25 \mathrm{~mm}$, and the diameter of the horizontal plane was $60 \mathrm{~mm}$. The bee was able to resolve all the large color marks simultaneously.

All shift flights recorded within the time course during which each of the four experimental phases was analyzed.

\section{Results}

Experiment 3 was designed to examine whether the introduction of individual color marks would restore the matching behavior in the roof setup. The data are summarized in Figures 7a-7d. In Phase 1a, we used small individual color marks that could be resolved by the bee's compound eye only during the approach and departure flights at a particular feeder. As shown in Figure 7a, within 1.5 days after the small color marks were introduced, the bee was still unable to rank its choice frequency to the relative reward rates $[F(3,18)=0.769$, n.s., Table 2p]. Thus, in contrast to individual odor marks, the bees did not learn that the small color marks predict the relative reward rates of the feeders.

A possible reason for this result is that to make its decision on the basis of the local cue color, the bee needs to discriminate among the feeders simultaneously. Therefore, in Phase $1 \mathrm{~b}$ of the experiment we exchanged the small color marks for large color marks, permitting the bee to see all the individually colored feeders at the same time. Foraging in this arrangement for a further day fi- 


\section{a choice (stay \& shift) behavior}

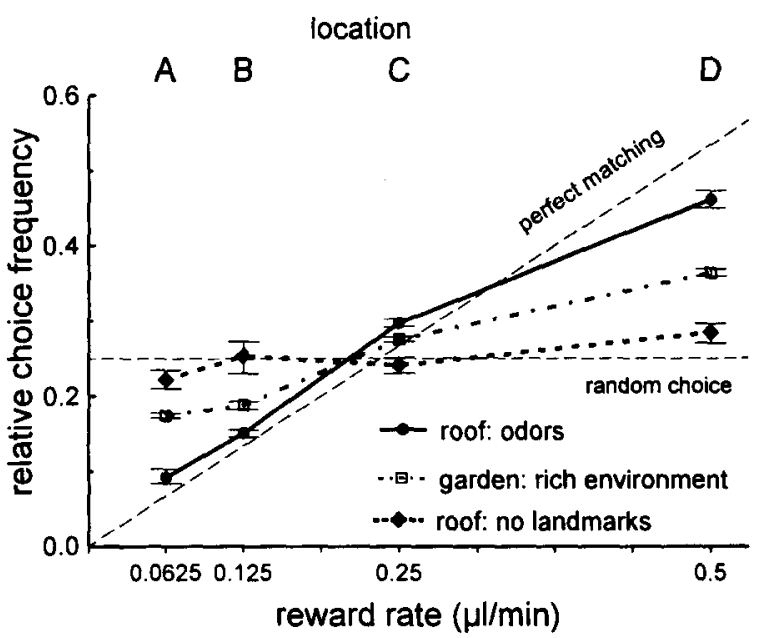

b

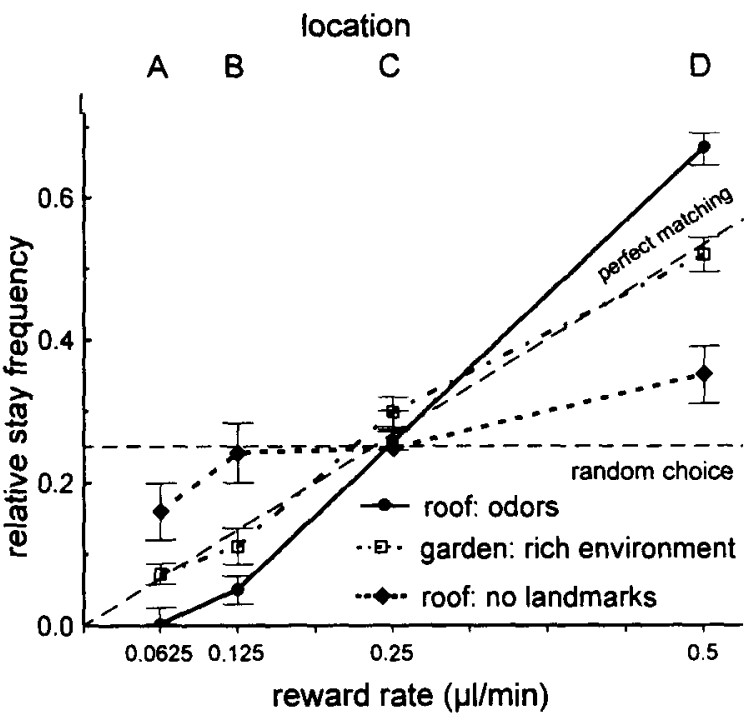

Figure 8. Event matching in different experimental situations: (a) choice (stay and shift) behavior in the roof setup with odors, $n=5,376$ decisions of 5 bees; the garden setup with a rich environment, $n=4,649$ of 14 bees; and the roof setup without landmarks, $n=2,019$ decisions of 6 bees. Choice proportions are plotted as mean values $\pm S E M$ (total number of each bee's stay and shift flights to all four feeders $=1$ ). The dashed lines give two theoretical extremes of choice strategy: perfect matching, as proposed by Herrnstein (1961), and random choice. (b) Stay behavior for the same experimental situations as in (a). Roof with odors, $n=1,197$ decisions of 5 bees; garden with rich environment, $n=1,065$ decisions of 14 bees; roof without landmarks, $n=362$ decisions of 6 bees. Choice proportions are plotted as mean values $\pm S E M$ (total number of each bee's stay flights to all four feeders $=1$ ).

nally resulted in ranking [Figure $7 b, F(3,18)=292.15$, $p<.0001$, Table $2 q]$. Thus, if the bee is to simultaneously discriminate among feeders by color, it must have sufficient information about the individual feeders and their relative reward rates to make the correct decisions. Compared with the experiment using local odor cues, the relative choice proportions were less steep $[\mathrm{A}, F(1,12)=$ $42.12, p<.0001 ; \mathrm{B}, F(1,12)=2.07$, n.s.; $\mathrm{C}, F(1,12)=$ $16.4, p<.0016 ; \mathrm{D}, F(1,12)=12.77, p<.0038$; see Figure 4a], but they were somewhat steeper than in the natural setting of the garden $[\mathrm{A}, F(1,19)=10.65, p<.004$; B, $F(1,19)=2.67$, n.s.; C, $F(1,19)=0.367$, n.s.; D, $F(1,19)=21.91, p<.0002$; see Figure $2 \mathrm{~b}]$.

To further determine the role of the color stimuli, we continued the experiments by rotating the feeders by $90^{\circ}$, leaving the same large color cues with the same flow rates as before (Phase 2). If color (like odor) was predictive of the relative efficiency of a particular feeder, we would expect an immediate switch of the choice frequencies to the new arrangement. However, as shown in Figure 7c, within the following $2 \mathrm{~h}$ there was no indication of a shift in the relative choice frequencies of the feeders $[F(3,18)=$ $28.74, p<.0001$, Table $2 \mathrm{r}$ ]. This result indicates that the bee is not able to use the color stimuli as a predictor of the efficiency of a particular feeder, but behaves as if it had to relearn the new arrangement (compare Figure 6b). Apparently, the individual colors did not themselves yield any information about the flow rate of a particular feeder. To test this, we removed the color marks and reinstated the former arrangement of flow rates (Phase 3 ). Ranking continued, although the bee was again (as in Phase 1) not able to discriminate among the four feeders by color [Figure $7 \mathrm{~d}, F(3,18)=50.29, p<.0001$, Table $2 \mathrm{~s}$ ]. Together, these data suggest that the bee used color discrimination to establish matching, but did not use the colors to maintain matching. This may also explain why rotating the arrangement did not result in an immediate shift in relative choice behavior.

To gain more information about the learning of the feeder positions, we took the last $4 \mathrm{~h}$ of both Phase $1 \mathrm{a}$, with small color marks, and Phase $1 \mathrm{~b}$, with large color marks, and closely examined the bee's departure, flight path, and landing behavior. In both experiments, its behavior on departure and during the flight path corresponded. Since we could not find any difference among the four individual feeders, we pooled the data of all feeders. In $77 \% \pm 5.6 \%$ SEM (small color marks, $n=812$ decisions of 7 bees) and $68 \% \pm 2.6 \%$ SEM (large color marks, $n=1,471$ decisions of 7 bees) of cases, the bee behaved in a positively phototactic manner prior to departure and left the feeder from a position marked by the reflection of the sun (a sector of $90^{\circ}$ ). It then swung around and performed a quick scan $(<0.5 \mathrm{sec})$ of the other feeders before moving into the chosen flight path. This the bee did within the first $10 \mathrm{~cm}$ after departure. A flight path is defined by a deviation of $\pm 10 \mathrm{~cm}$ from a straight 
connecting line between the feeders. The bee could, therefore, see the targets (shapes of small color marks included) even if this did not always lead to correct choices to perform a ranking. On arriving at the target feeder, the bee changed its body angle before landing at and entering the feeder. In the case of the small color marks, we found a random distribution $\left(0^{\circ}-360^{\circ}\right)$ of landing angles, which is the same as that observed for the experiment with stones and large green color disks when ranking failed. In the situation with large color marks, the bees made $65.1 \% \pm 3.1 \% S E M$ of landings in the four sectors north, west, south, and east $\pm 15^{\circ}$, compared with $34.9 \%$ in the sectors northwest, southwest, southeast, and northeast $\pm 15^{\circ}$. All four sectors - north, west, south, and eastwere chosen equally frequently $[F(3,18)=0.487$, n.s.], and in addition, we could not find any difference among the feeders. This phenomenon of multiple selective viewing is characteristic only of those roof experiments in which the bee was able to learn the location of the feeders. The apparatus in the roof experiments was adjusted in such a way that the sides of the square formed by the four feeders were parallel to the earth compass axes. Thus it is difficult to argue whether the multiple selective viewing was adjusted to the square formed by the feeders or adjusted to the earth compass axes.

\section{Discussion}

In Experiment 3, we examined the possible role of a particular local cue, color, in matching. We found that in a four-feeder arrangement lacking all close landmarks, the introduction of individual local color marks could restore matching only if the bee was able to discriminate among the feeders simultaneously. Previous studies have shown that bees perform best when they see colors during the approach flight toward a feeding place (Grossmann, 1970; Menzel, 1968; Opfinger, 1931), and that they are able to remember a color after a single learning trial (Menzel, 1968). Therefore, it has been widely accepted that color, being contiguous with the intake of sucrose solution, could serve as a CS in a form of classical conditioning (Menzel, 1985, 1990). Thus it was unexpected that the small color marks (unlike odor) did not predict the relative reward rates. The apparent lack of ranking in the situation with small color marks may be explained in two ways: (1) Unlike odor, color by itself cannot function as a CS for sucrose, or it may be that it merely predicts the presence but not the quality of the rewarding stimulus. (2) Color can be learned only in relation to other cues providing information about the location of the feeders. Since the bee was able to rank after the introduction of the large color marks, we favor the second view, because it seems that simultaneous access to the colors is important for making choices. Another interesting observation is an apparent difference in the choice behavior between arrangements using odors and small color marks: With local odor marks, the bees frequently retreated from a selected feeder after they perceived the local odor signal and visited an alternative feeder. With small color marks, the bee never retreated from a selected feeder, suggesting that the perception of the color close to the feeder entrance had no direct impact on choice behavior. Furthermore, as the rotation experiment suggests, the colors themselves did not continue to provide information about the flow rates of the feeders. Thus it seems that the colors helped to identify some other location cues to the specific feeders. Color may have been just one component of a complex configuration that finally contained enough information to locate each feeder. Which cues the bee actually used is unclear. Perhaps some incidental features of the setup (shadows, dirt marks, etc.) serving as local landmarks in combination with the local cue color helped to identify the location. Neither can we exclude the possibility that the bee is able to use distant landmarks, its suncompass, or the magnetic field in combination with the colors. The results of Phase 3 of the experiment are surprising. It appears that the colors merely acted as facilitators to establish matching, but not to maintain matching. This could mean that after matching has been established, it becomes independent of certain stimuli used initially. Even if we consider the possibility that the bee was able to use its own odor marks for recognition of the individual feeders (Corbet, Kerslake, Brown, \& Morland, 1984; Giurfa \& Núñez, 1992), it seems highly unlikely that this was sufficient to effect choice behavior and to support matching. The results obtained in the reduced-cue garden setup (Experiment 1 ) indicate that after matching for 1 day in a given arrangement, long-term behavioral changes develop, at least with respect to the flight paths, which become progressively more direct. Furthermore, in all roof experiments in which the bee was able to learn the location of the feeders, long-term changes were found, whereby the bee aimed its body axis by using the sides of the square formed by the feeders or by using the earth compass axes. The resulting four directions were used equally frequently to achieve a multiple but selective viewing of the targets.

Other branches of research in the areas of navigation and orientation concentrate on the initial influence of landmarks and compass systems. Lehrer (1991) described the "turn back and look behavior" of bees upon exiting a feeding dish. Collett and Baron (1994) described how the magnetic field of the earth is used by the bees to face mainly south while searching for a feeder to which they were previously trained. We add the phenomenon of multiple selective viewing as a possible basis that allows more reliable decision making in multiple-choice situations in which the bee approaches one target from several possible directions in a sequence of visits.

\section{GENERAL RESULTS}

Up to this point, we used the criterion "ranking of shift flights" to describe the results of Experiments 1-3. We were forced to use this approach because, in most experimental situations, imperfect matching was observed, 
and, in addition, the degree of deviation from perfect matching depended strongly on the experimental parameters. The deviations from strict matching in a quantitative sense could be explained as sensory biases and by informational constraints. In order to gain complete information about the different flow rates of sucrose solution, the bee has to monitor not only each choice and the complex stimuli experienced during this choice, but also each amount of reward obtained over relatively long periods of time. Figure 8 gives three typical examples and two theoretical functions of a possible choice strategy (i.e., random choice and perfect matching) on a linear scale of reward to compare our results with those of Herrnstein (1961). Since Herrnstein did not distinguish between stay and shift behavior, we first examined the allocation of choice as a sum of all events (both shift and stay flights, Figure 8a) and then we examined the stay flights separately (Figure 8b) in order to elucidate their differential role as a component of overall choice. The best matching performance was found in the roof experiment with odors, although there was still a deviation from perfect matching [multinomial test $\chi^{2}(3,1011)=25.68, p<$ $.00001]$. The poorest performance was found in the roof control without landmarks, where the ranking of shift flights failed (Figure $3 \mathrm{a}$ ) and the matching effect was due only to the ranking of stay flights [Figure $8 \mathrm{~b}, F(3,15)=$ $13.75, p<.00014$, Table 2t]. Interestingly, we found that there was no experimental situation in which the bees were completely unable to make use of the graded reward distribution, since they were always able to distinguish and revisit the feeder just visited. The ranking function for stay behavior in the experiments with odors was even steeper than for stay behavior in the rich garden environment $[F(1,19)=271.40, p<.00001]$, and thus steeper than the matching law would predict.

In all situations in which the bee was able to learn the location of the feeders, the choice functions were similar. A typical example is the garden experiment with a rich environment. Although the absolute number of stimuli to discriminate among the feeders was highest in this paradigm, the matching performance was less than predicted by the matching law. Only the proportions of stay flights agreed with a linear matching function, as already described by Greggers and Menzel (1993). Table 1 gives the choice proportions for all other experimental groups not shown in Figure 8.

\section{GENERAL DISCUSSION}

The experimental arrangement used in this study allowed us to manipulate the matching behavior of honeybees in order to examine the role of certain stimuli and the kind of learning that takes place in the different situations selected. The results show that there is no unique stimulus modality that provides matching. Rather, the bee is able to make use of very different mechanisms to solve the task. Our results reveal at least two fundamen- tally different forms of memory, both of which affect feeding behavior. In the first case, matching is based on a very elementary form of learning. Following the rules of classical conditioning, odors become predictive of the amount of sucrose available. In this case, memories are updated directly with information on the different reward rates. Thus we propose that the perception of a single odor releases feeding with a certain probability. In the second case, matching is based on a kind of configural learning. The bee memorizes the different reward rates indirectly by learning the location of the feeders using colors or landmarks. We suggest that more complex mechanisms underlie the learning of a location. This may also involve the storage of certain snapshots within or around the setup that would not need to include a direct view of the feeders (Cartwright \& Collett, 1983, 1987; Wehner, 1971, 1972). In turn, recognition of a location might activate a retrieval system in which the memories of the feeders are compared simultaneously. Probably both forms of memory interact to result in efficient feeding behavior during foraging under natural conditions.

Another objective of this research was to relate components of natural behavior to those of laboratory experiments that have investigated the basic rules and cellular mechanisms of bee learning and memory (for a review, see Hammer \& Menzel, 1995). It has been a major concern that restrained bees fail to learn colors in a classical conditioning of the proboscis extension response (PER)that is, when colors are presented as the CS and sucrose solution is presented as the US. As reported by Kuwabara (1957) and Masuhr and Menzel (1972), a conditioned response to colored light (CS) is established within an average of about 30 to 40 conditioning trials, with the maximal learning rate reaching $50 \%$. This indicates that a conditioned response can develop over a large number of trials. However, this is by no means comparable with the fast (one-trial) color learning of free-flying bees (Menzel, 1968), which suggests that another mechanism underlying learning color in the natural setting must exist. As mentioned above, previous studies (Couvillon et al., 1991; Gould, 1988; Grossmann, 1971; Hannes, 1930; Lehrer, 1991; Menzel, 1968; Opfinger, 1931) have indicated that color may not necessarily serve as a CS in a form of classical conditioning, since learning during and after sucrose intake is possible. Grossman's (1971) studies have also shown that the color presented after landing has no informative value, even though the color was shown before the intake of sucrose solution. Our results further indicate that colors do not function as stimuli that by themselves are directly associated with the sucrose reward and do not predict the efficiency of a food source. Rather, they are used to identify a location in combination with other colors or landmarks whose spatial relation is learned during the flight. Thus we may be dealing with stimulus-stimulus associations (Rescorla \& Colwill, 1989; Rescorla \& Solomon, 1967) between the local cue color and nearby landmarks (producing a visual image), 
and response-reinforcer associations, with the response being to match body position with the stored retinal image during the flight. Therefore, as shown by the experiment with small color marks, a single color is also not sufficient to code for locating a feeding place. In contrast to colors, in the classical PER conditioning bees learn to associate odors with sucrose solution after a single conditioning trial (Bitterman et al., 1983; Frings, 1944; Takeda, 1957, 1961). According to the results described above, such direct associations between odor and sucrose reward also seem to be a component of natural foraging behavior. Thus with respect to both colors and odors, the results obtained from restrained and free-flying bees are likely to be closely related.

\section{REFERENCES}

Bitterman, M. E. (1976). Incentive contrast in honey bees. Science, 192, 380-382.

BitTERMAN, M. E. (1988). Vertebrate-invertebrate comparisons. In H. J. Jerison \& I. Jerison (Eds.), Intelligence and evolutionary biology (pp. 251-276). Berlin: Springer-Verlag.

Bitterman, M. E., Menzel, R., Fietz, A., \& Schäfer, S. (1983). Classical conditioning of proboscis extension in honeybees (Apis mellifera). Journal of Comparative Psychology, 97, 107-119.

Cartwright, B. A., \& Collett, T. S. (1983). Landmark learning in bees: Experiments and models. Journal of Comparative Physiology, 151, 521-543.

CARTWRIGHT, B. A., \& ColletT, T. S. (1987). Landmark maps for honeybees. Biological Cybernetics, 57, 85-93.

Catania, A. C. (1963). Concurrent performances: A baseline for the study of reinforcement magnitude. Journal of the Experimental Analysis of Behavior, 6, 299-300.

Cheverton, J., KACELNiK, A., \& Krebs, J. R. (1985). Optimal foraging: Constraints and currencies. In B. Hölldobler \& M. Lindauer (Eds.), Experimental behavioral ecology and sociobiology (Fortschritte in der Zoologie, Vol. 31, pp. 109-126). Stuttgart: Fischer.

COLLETT, T. S. (1995). Making learning easy: The acquisition of visual information during the orientation flights of social wasps. Journal of Comparative Physiology A, 177, 737-747.

ColletT, T. S. (1996). Insect navigation on route to the goal: Multiple strategies for the use of landmarks. Journal of Experimental Biology, 199, 227-235.

Collett, T. S., \& Baron, J. (1994). Biological compasses and the coordinate frame of landmark memories in honeybees. Nature, 368 , 137-140.

Corbet, S. A., Kerslake, C. J. C., Brown, D., \& Morland, N. E. (1984). Can bees select nectar-rich flowers in a patch? Journal of Apicultural Research, 23, 234-242.

Couvillon, P. A., \& Bitterman, M. E. (1982). Compound conditionIng in honeybees. Journal of Comparative \& Physiological Psychology, 96, 192-199.

Couvillon, P. A., Leiato, T. G., \& Bitterman, M. E. (1991). Learning by honeybees (Apis mellifera) on arrival at and departure from a feeding place. Journal of Comparative Psychology, 105, 177-184.

Dickinson, J. A. (1994). Bees link local landmarks with celestial compass cues. Naturwissenschaften, 81, 465-467.

Dill, M., \& HeIsenberG, M. (1995). Visual pattern memory without shape recognition. Philosophical Transactions of the Royal Society of London. Series B, 349, 143-152.

Dill, M., Wolf, R., \& Heisenberg, M. (1995). Behavioral analysis of Drosophila landmark learning in the flight simulator. Learning \& Memory, 2, 152-160.

FRINGS, H. (1944). The loci of olfactory end-organs in the honey-bee. Apis mellifera Linn. Journal of Experimental Zoology, 97, 123-134.

FRISCH, K. VON (1949). Die Polarisation des Himmelslichtes als orientierender Faktor beı den Tänzen der Bienen. Experientia, 5, 142-148.
FRISCH, K. von (1967). The dance language and orientation of bees. Cambridge, MA: Harvard University Press.

Giurfa, M., \& NúÑEZ, J. A. (1992). Honeybees mark with scent and reject visited flowers. Oecologia, 89, 113-117.

Giurfa, M., Vorobyev, M., KeVAN, P., \& Menzel, R. (1996). Detection of coloured stimuli by honeybees: Minimum visual angles and receptor specific contrasts. Journal of Comparative Physiology A, 177, 699-709.

GouLD, J. L. (1984). The natural history of honey bee learning. In P. Marler \& H. Terrace (Eds.), The biology of learning (pp. 149-180). Berlin: Springer-Verlag.

GouLD, J. L. (1988). Timing of landmark learning by honey bees. Journal of Insect Behavior, 1, 373-378.

GregGers, U., \& MENZEL, R. (1993). Memory dynamics and foraging strategies of honeybees. Behavioral Ecology \& Sociobiology, 32, 17-29.

GrossmanN, K. E. (1970). Erlernen von Farbreizen an der Futterquelle durch Honigbienen während des Anfluges und während des Saugens. Zeitschrift für Tierpsychologie, 27, 553-562.

GrossmanN, K. E. (1971). Belohnungsverzögerung beim Erlernen einer Farbe an einer künstlichen Futterstelle durch Honıbienen. Zeitschrift für Tierpsychologie, 29, 28-41.

GrossmanN, K. E. (1973). Continuous, fixed-ratio, and fixed-interval reinforcement in honey bees. Journal of the Experimental Analysis of Behavior, 20, 105-109.

HAMMER, M., \& MEN7EL, R. (1995). Learning and memory in the honeybee. Journal of Neuroscience, 15, 1617-1630.

HaNNES, F. (1930). Über die verschiedenen Arten des "Lernes" der Honigbiene und der Insekten überhaupt. Zoologische Jahresbücher: Abteilung für allgemeine Zoologie und Physiologie der Tiere, 47, 89150.

HeinRICH, B. (1985). Learning in invertebrates. In P. Marler \& H. Terrace (Eds.), The biology of learning (pp. 135-147). Berlin: Springer-Verlag.

HERRNSTEIN, R. J. (1961). Relative and absolute strength of response as a function of frequency and reinforcement. Journal of the Experimental Analysis of Behavior, 4, 267-272.

KaCel NiK, A., Houston, A. I., \& SChmid-Hempel, P. (1986). Centralplace foraging in honey bees: The effect of travel time and nectar flow on crop filling. Behavioral Ecology \& Sociobiology, 19, 19-24.

Kuwabara, M. (1957). Bildung des bedingten Reflexes von Pavlovs Typus bei der Honigbiene, Apis mellifica. Journal of the Faculty of Science, Hokkaido University, 13, 458-464

LEHRER, M. (1991). Bees which turn back and look. Die Naturwissenschaften, 78, 274-276.

LINDAUER, M. (1963). Allgemeine Sinnesphysiologie: Orientierung im Raum. In H. Giersberg et al. (Eds.), Hormone (Fortschritte in der Zoologie, Vol. 16, pp. 58-140). Stuttgart: Fischer.

MASUHR, T., \& MENZEL, R. (1972). Learning experiments on the use of side-specific information in the olfactory and visual system in the honeybee (Apis mellifica). In R. Wehner (Ed.), Information processing in the visual system of arthropods (pp. 315-322). Berlin: Springer.

MenZel, R. (1968). Das Gedächtnis der Honigbiene für Spektralfarben: I. Kurzzeitiges und langzeitiges Behalten. Zeitschrift für vergleichende Physiologie, 56, 22-62.

MENZEL, R. (1985). Learning in honey bees in an ecological and behavioral context. In B. Hölldobler \& M. Lindauer (Eds.), Experimental behavioral ecology and sociobiology (Fortschritte in der Zoologie, Vol. 31, pp. 55-74). Stuttgart: Fischer

MENZEL, R. (1990). Learning, memory, and "cognition" in honey bees. In R. P. Kesner \& D. S. Olton (Eds.), Neurobiology of comparative cognition (pp. 237-292). Hillsdale, NJ: Erlbaum.

Menzel, R., \& ERBer, J. (1972). The influence of the quantity of reward on the learning performance in honeybees. Behavior, 41, 27-42.

Menzel, R., \& GregGers, U. (1985). Natural phototaxis and its relationship to color vision in honeybees. Journal of Comparative Physiology, 157, 311-321.

OPFINGER, E. (1931). Über die Orientierung der Biene an der Futterquelle. Zeitschrift für vergleichende Physiologie, 15, 432-487.

OPFINGER, E. (1949). Zur Psychologie der Duftdressuren bei Bienen Zeitschrift für vergleichende Physiologie, 31, 441-453.

REAL, L. A. (1991). Animal choice behavior and the evolution of $\operatorname{cog}$ nitive architecture. Science, 253, 980-986. 
ResCorla, R. A., \& ColwILl, R. M. (1989). Associations with anticipated and obtained outcomes in instrumental learning. Animal Learning \& Behavior, 17, 291-303.

ResCORLA, R. A., \& Solomon, R. L. (1967). Two-process learning theory: Relationships between Pavlovian conditioning and instrumental learning. Psychological Review, 74, 151-182.

SeELEY, T. D. (1989). The honey bee colony as a superorganism. American Scientist, 77, 546-553.

SrgurdSon, J. E. (1981a). Automated discrete-trials techniques of appetitive conditioning in honey bees. Behavior Research Methods \& Instrumentation, 13, 1-10.

SiguRdSON, J. E. (1981b). Measurement of consummatory behavior in honey bees. Behavior Research Methods \& Instrumentation, 13, 308-310.

TAKEDA, K. (1957). Studies on conditioned reflex in the honey bee, Apis mellifica. Zoological Magazine Japan, 66, 441-449.
TAKEDA, K. (1961). Classical conditioned response in the honey bee. Journal of Insect Physiology, 6, 168-179.

Thuisman, F., Peleg, B., Amitai, M., \& Shmida, A. (1995). Automata, matching and foraging behavior of bees. Journal of Theoretical Biology, 175, 305-316.

WEHNER, R. (1971). The generalization of directional visual stimuli in the honey bee, Apis mellifera. Journal of Insect Physiology, 17, 1579-1591.

WEHNER, R. (1972). Dorsoventral asymmetry in the visual field of the bee, Apis mellifica. Journal of Comparative Physiology, 77, 256-277. WEHNER, R., Michel, B., \& ANTONSON, P. (1996). Visual navigation in insects-Coupling of egocentric and geocentric information. Journal of Experimental Biology, 199, 129-140.

(Manuscript received August 7, 1996; revision accepted for publication May 20,1997.) 